\title{
Aitor Bolaños de Miguel (ed.), Metahistoria: 40 años después. Ensayos en homenaje a Hayden White. Logroño: Siníndice, 2014, 260 págs.
}

Cuenta Simon Karlinsky que bastantes años después de la muerte del gran escritor ruso Nikolai Gogol, su madre no se limitaba a presumir de la grandeza literaria de su retoño sino que desbarraba hasta el punto de decir que su hijo había sido el inventor, entre otras cosas, de la máquina de vapor. ${ }^{1}$ Evidentemente, pese al amor materno, Gogol no fue el inventor de la máquina de vapor. Del mismo modo, creo que puede afirmarse que, pese al amor de sus admiradores, tampoco fue Hayden White quien la inventó.

\section{II}

En la actualidad, resulta una obviedad decir que Hayden White es autor, entre otros, de tres libros sumamente relevantes en el campo de la teoría de la historia y del pensamiento historiográfico, que en mi opinión funcionan de un modo articulado, casi como un todo: Metahistory (1973), Tropics of Discourse (1978) y The Content of the Form (1987). Nadie puede discutir el extraordinario valor de estas obras ni dar un rodeo en torno a ellas y hacer como si no existieran. Hayden White encarna uno de los intentos más lúcidos a la hora de pensar la historia desde la perspectiva que fue forjándose en esa nebulosa que sería denominada como "giro lingüístico".

Por su lado, el conjunto de artículos propuesto por Aitor Bolaños en su Metahistoria: 40 años después, es sin duda una guía interesante a las aportaciones del autor norteamericano y a sus reverberaciones en esos 40 años de existencia, aunque desde el principio (p. 14) nos encontremos con una afirmación que resulta sorprendente:

\section{[...] hemos intentado dar cabida a distintas y variadas posiciones críticas, si bien es verdad que todos los trabajos presentes en este homenaje (salvo uno) denotan una evidente simpatía (que puede rayar en la empatía) por la obra del filósofo USA americano y muchos de ellos una matizada y elaborada admiración [...].}

Todos menos uno... La oveja negra, en este caso, es José Carlos Bermejo Barrera, curiosamente el teórico de la historia más importante de España, que por otro lado -en su contribución a este libro (pp. 59-85), publicada por vez primera hace ya más de 20 años pero plenamente vigente- no hace sino sopesar el valor de los planteamientos del autor dentro de un contexto teórico más amplio.

Todos menos uno... ese es el primer problema que se abre no ya en este libro sino en todos los libros que se dedican a las celebraciones. El que no celebra acaba convirtiéndose en un aguafiestas. En mi opinión es precisamente ahí donde me parece que la teoría de la historia está perdiendo su gran batalla.

Hace bastantes años escribí un libro, aún inédito, cuyo título era Po-ética Teórica. Fragmentos de Literatura y Teoría, algunas de cuyas piezas sueltas ruedan por mi sitio en Academia.edu, y que empezaba así:

\footnotetext{
${ }^{1}$ Simon Karlinsky, The Sexual Labyrinth of Nikolai Gogol (Chicago: The University of Chicago Press, 1976), 9 .
}

ISSN 2174-4289 
En la teoría, el aguafiestas es el centro de la fiesta. La teoría es provocación, desafío, radicalidad. Teorizar implica dejar de lado los pensamientos y los usos (políticamente) correctos; saltar por encima de convicciones y asunciones... también quebrar algunas reglas del juego, de ahí que se vea como algo tan peligroso. Teorizar es plantear que no todo resulta tan evidente como parece, que casi nada está claro ni en el plano filosófico ni en el social ni en el político: por ello, aquellos que se sienten seguros en el orden actual (y que viven de él) lanzan contra el teórico el dardo más emponzoñado y que más pone en guardia al público, a saber, la acusación de conservadurismo y de complicidad con la reacción y el fascismo. Y, no obstante, jay de aquel teórico al que nunca le hayan hecho alguna de estas imputaciones! Teorizar es siempre nadar contra corriente, sea ésta la que sea. Como decía Benjamin, se trata de cepillar la historia a contrapelo; sólo así se logrará reabrir lo que se hallaba cerrado, reestudiar lo que se pensaba ya estudiado, denunciar lo que se consideraba archivado. El teórico no aspira a la verdad sino a la problematización de las verdades. El teórico agua la fiesta a la fe en la armonía de la cosas (Estado, Razón, Ciencia...) y socava lo "real" en sus discursos, sean éstos filosóficos, históricos, políticos, científicos... Y cuando el hambre de cátedras y el nuevo reparto patrimonial de los puestos universitarios consigan institucionalizar la teoría como (otra) disciplina académica (más), anulando con ello su potencial y disecándola en forma de manuales, la teoría, aun con otro nombre, habrá de generar su propia Dialéctica de la Teoría y luchar contra los simulacros de sí misma.

Son muchas las disciplinas, concebidas hace siglos que, como la historia, agonizan, se petrifican por haber petrificado su forma. Estos ensayos buscan precisamente violentar esa forma, diversificarla, ligarla de manera inextricable a los textos con y sobre los que reflexiona de modo que no se pueda entender sin ellos; en definitiva, buscan convertir al pensamiento en una in-disciplina.

Aunque me sonroje en parte esta prosa un tanto adolescente y exaltada, en el fondo creo que el contenido sigue funcionando a la perfección como marco de lo que en esta reseña quiero proponer: el gran interés de la obra de Hayden White, en especial de su Metahistory, se ve socavado en la actualidad -pero, en realidad, desde hace ya bastantes años- por un "culto whiteano", que en realidad no es un culto al propio autor sino un culto a sí misma de la iglesia que se creó a raíz de su magisterio.

Hayden White, cuyas propuestas de análisis de los textos históricos resultaron un verdadero acicate para la teoría de la historia, ha acabado viendo sus trabajos como Sagradas Escrituras que han contribuido a la conversión de una interesantísima práctica intelectual conocida como Teoría de la historia en un aburrido tran-tran académico que casi hace divertida a la propia academia histórica. El almost scholastic sense que Hans Kellner le atribuye a las categorías whiteanas (p. 9) no parece sino un trasvase inconsciente del sentido escolástico que han tomado aquellas en manos de sus apóstoles. La "provocación", no solo como incitación o estímulo a la reflexión sino también como irritación (véase p. 143 y ss.), que Anaclet Pons reivindica en su artículo como uno de los valores fundamentales del legado de White y que sin duda habría de ser uno de los activos más importantes del teórico, ${ }^{2}$ resulta hoy poco más que un bonito cuadro antiguo de temática revolucionaria colgado en la pared de otra aburrida universidad.

El artículo "La arquitectura de la imaginación" -insisto, ya antiguo- de José Carlos Bermejo - pese a todo muy oportunamente incluido por Bolaños-, muestra a la

\footnotetext{
${ }^{2}$ Así lo refrenda José Enrique Ruiz-Domènec en su capítulo "Hecho y significado: releer a Hayden White" (pp. 153-165), cuando pone al pensador norteamericano como un antídoto ante la desidia burocrática que inunda el saber histórico al plantear argumentos tan fuertes como que los historiadores no solo desean contar la verdad sobre el pasado sino que también desean dotarle al pasado de significado (véase p. 163).
}

ISSN 2174-4289 
perfección el punto medio de reconocimiento y crítica que merece la creación de Hayden White. El valor de Metahistory es su carácter partisano, comprometido y valiente. En cierta medida y salvando las distancias, semejante al Orientalism de Edward Said; un libro que podría permitirse algunas lagunas y deficiencias analíticas en el intento por centrar todas sus energías en la radical exposición de sus posiciones para generar una explosión que hiciera ineludible la apertura de un debate y la reflexión sobre aquello que se pensaba seguro y cierto.

Reconocer el valor de la teoría de White implica también -como casi siemprereconocer sus lagunas... y esas son las que elucida con acierto el texto de Bermejo. La perspectiva formalista whiteana que desvela el carácter narrativo de la historiografía del s. XX, que opera como epítome de toda la historiografía de todos los tiempos (lo cual, como señala este autor, no deja de ser también inexacto), no debería ser un obstáculo para aceptar que también existen otras perspectivas desde las que analizar el relato de los historiadores; sin ir más lejos, la perspectiva psicológica, la sociológica o la epistemológica. De hecho, el propio White hace gala de un cierto sesgo epistemológico (¿un epistemologismo estratégico [que diría Spivak]?) afirmando que la historia tendría a veces un carácter protocientífico (véase p. 78).

La dualidad reconocimiento-crítica encarnada por el artículo de Bermejo permite cuando menos matizar afirmaciones a la vez entusiastas y desproporcionadas como las que realiza Jaume Aurell en su artículo "La recepción de Metahistoria: de la retórica a la ética" (pp. 25-57), quien plantea que las consecuencias teóricas y prácticas de la "revolución epistemológica" de Hayden White serían, en primer lugar, el proporcionar "soporte teórico" a un resurgimiento de la narrativa en historiografía que en el texto de Aurell se describe así:

\begin{abstract}
Los historiadores más prestigiosos se lanzaron a la construcción de obras históricas rompiendo la tradición de las grandes monografías estructuralistas ([...] Mediterráneo de [...] Braudel) y marxistas ([...] formación de la clase obrera [...] Thompson) y apostando decididamente por la narración. Los ejemplos más característicos llegaron del ámbito del modernismo: La descripción de la vida cotidiana de un pueblecito pirenaico por parte de Emmanuel Le Roy Ladurie, el inverosímil pero documentado relato del campesino Martin Guerre de la historiadora norteamericana Natalie Z. Davis [...] y la narración del proceso inquisitorial del molinero Menocchio por parte del historiador italiano Carlo Ginzburg (p. 29).
\end{abstract}

En segundo lugar, según Aurell, gracias a Metahistory los historiadores habrían prestado más atención a "campos fronterizos de la historia con la crítica literaria y la neo-hermenéutica de Paul Ricoeur y Michel de Certeau"; y "de un modo indirecto y no buscado por su autor" habría propiciado que la disciplina histórica se viera invadida por "las teorías posmodernas asociadas al giro lingüístico, el post-estructuralismo y el deconstruccionismo" (p. 30).

No sé si Le Roy Ladurie, Ginzburg o tantos autores que quedan englobados en ese conjunto señalado por Aurell sentirían a White como su "soporte teórico"; en todo caso, resulta difícil pensar que el "soporte teórico" de una obra se aplique con posterioridad o por parte de alguien cuyo pensamiento aún no se conoce. Raro resultará también que un autor cuya recepción ha sido tan tardía fuera de Estados Unidos, como puede verse en 
las propias páginas del libro de Bolaños, ${ }^{3}$ parezca haber contribuido a cambiar tantísimas cosas en los años 70 y 80 ¡un tiempo en el que su lectura era aún residual! Atribuirle cosas como el apadrinamiento de la otrora en boga "historia de las mentalidades", la lectura de Ricoeur o de de Certeau, así como la introducción del postestructuralismo y el deconstruccionismo... me hace volver a recordar de nuevo a la madre de Nikolai Gogol. Más bien creo que esos fenómenos que señala Aurell son hijos de los mismos padres que el libro de White; flores diversas desperdigadas por un mismo campo.

Por otro lado, una cosa es que White propusiera efectivamente un acercamiento nuevo al texto histórico, que ponía boca abajo el poder absoluto de la perspectiva epistemológica a la hora de considerar los textos históricos (véase Bermejo, p. 84), y otra muy distinta es dibujar a un Hayden White airado que tiene entre ceja y ceja a la tríada maligna formada por marxismo, estructuralismo y cuantitativismo, que trataba de "tecnificar" el lenguaje de la narración histórica (véase Aurell, pp. 42-43). El propio Aurell es muy consciente de "el peso real del presente en la labor de quienes leen el pasado", y entrelíneas de su dibujo de White ese dictum parece pesar bastante. ${ }^{4}$ White se revolvería contra las mismas cosas que el propio Aurell y apoyaría las mismas cosas que él; así lo más interesante del norteamericano no serían tanto sus conclusiones en torno al carácter narrativo de la historia o sus implicaciones teóricas sino más bien su "giro ético":

Los nuevos comentadores han puesto de manifiesto que White decidió usar las formas retóricas para desenmascarar el aprisionamiento de la práctica histórica en las ideologías lo que White había definido desde el principio como "el peso de la historia" [...]-. Si el objetivo de White era liberar a la historia de ese "fardo", codificado en los "realismos" del pensamiento histórico convencional, ¿por qué no privilegiar simplemente el argumento filosófico y ético, haciendo desaparecer el "bypass" retórico? (p. 53).

No deja de resultar sorprendente la perspectiva de Aurell para quien todos esos logros whiteanos de los que nos ha estado hablando a lo largo de su artículo, y alrededor de los cuales giran buena parte de los artículos del libro de Bolaños, no serían en definitiva sino un "bypass" retórico que en realidad apuntaría a otras metas... ¡redentoras! (véase p. 54). No sé por qué me viene a la mente, al leer esto, el relato sobre el Robinson soviético de los geniales Ilf y Pietrov. ${ }^{5}$

\section{III}

Al margen de los artículos de Bermejo y Aurell, la compilación de Bolaños exhibe un cuerpo de ensayos más o menos interesantes y, en buena medida, complementarios de Miguel Ángel Cabrera, Manuel Cruz, Vladimir López Alcañiz, Anaclet Pons, Enrique Ruiz-Domènec, Pedro Ruiz Torres, Justo Serna, Verónica Tozzi y Nicolás Lavagnino y el propio Aitor Bolaños, para acabar con dos textos del propio White: "Thoughts on the Practical Past" y "How I did not write Metahistory", que al igual que el prólogo de Hans Kellner bien habrían merecido aparecer traducidos.

\footnotetext{
${ }^{3}$ Para el caso de España, además del aludido artículo de Bermejo, puede acudirse en especial al artículo "Whiteología(s)" de Aitor Bolaños (pp. 213-238), por lo demás una síntesis interesante y útil sobre la recepción de la obra del autor norteamericano.

${ }^{4}$ Jaume Aurell, La escritura de la memoria (Valencia: Prensas Universitarias de Valencia, 2005), 17.

${ }^{5}$ Iliá Ilf y Yevgueni Pietrov, “КакСоздавалсяРобинзон”, en 1001 День, илиНоваяШахерезада (Моscú: MiK, 1994), 357-61.
}

ISSN 2174-4289 
Entre ellos, destacaré el artículo "Hayden White y el debate sobre el conocimiento histórico" (pp. 87-106) de Miguel Ángel Cabrera, en el que este autor realiza una muy loable síntesis de las principales ideas y conceptos desplegados por White en su Metahistory. Por sí solo este artículo le proporcionará un mapa sumamente útil a aquellos que aún no se hayan iniciado en el autor. Al mismo tiempo, Cabrera plantea algunas de las críticas que se le han realizado a White aunque en un tono de defensa. Quizás sea esta la parte menos acabada de su escrito. También quiero hacer mención al texto de Vladimir López en "Una historiografía de la liberación" (pp. 123-139), en mi opinión, uno de los artículos más originales y acabados del libro, con una deliciosa escritura y una ágil e interesante contextualización del momento intelectual en el que surge Metahistory. En él, resulta muy interesante el modo en el que se describe cómo una de las grandes intuiciones de White fue el ser capaz de ver que la ambigüedad metodológica de la historia era, más que un obstáculo, una oportunidad para la reflexión (p. 128).

\section{IV.}

Es, desde mi punto de vista, indudable que los sucesivos homenajes a Metahistory, décimo-vigésimo-trigésimo-cuadragésimo aniversario... arf! han contribuido decisivamente a tener a este autor en el centro de la escena periódicamente como si fuera el Mesías. Con ello tiene que ver, por un lado, la pujanza, o mejor, el dominio omnímodo de la teoría americana a través de revistas como History and Theory, que actúan como empresas de marketing para sus propias ideas y su cultura centrada casi en exclusiva en el mundo anglófono. En la actualidad nos hallamos tan plegados al mundo teórico (y no solo teórico) anglosajón que todo lo que viene de allí nos parece ser TODA la realidad del pensamiento universal. En general, las humanidades se hallan hoy presas del fetichismo de la lengua inglesa. La funesta política educativa actual que aboca a un bilingüismo falso y beocio prepara ya a nuestras hijas e hijos (en el caso de que tengan la oportunidad de realizar estudios superiores) a moverse invariablemente en un contexto intelectual anglosajón, a pasar por el cedazo de las revistas anglosajonas, a verse inmersas e inmersos en sus debates y seguramente, en el caso de que se dediquen a la teoría de la historia, a que empiecen a vestir casi desde la infancia el hábito de los monaguillos que celebrarán los próximos aniversarios de San Hayden White.

Por otro lado, ello tiene que ver también con la propia esclerosis de esa teoría de la historia americana que desde allí se extiende ineluctablemente al resto del mundo académico. La ágil y chispeante teoría de la historia de los 70 y 80, en todas partes, se ha convertido hoy en día en un muermo que ha enterrado todo el vigor con el que arrancó esta práctica que parecía indomable... No puede haber mejor ilustración de lo que Weber denominaría Veralltäglichung (rutinización o cotidianización), aplicado a la praxis teórica, que este pétreo día de la marmota de los homenajes a Hayden White.

La figura de White (sin negarle de ningún modo su importancia) está sobredimensionada por una academia americana que es cada vez más alérgica a leer lo que se está haciendo en otras partes del mundo no anglófono (¿existe ya tal cosa?), y muy particularmente en Europa. 
Al volver, aniversario tras aniversario, sobre la figura de Hayden White pareciera que se buscan en él las raíces de algo... Pero ¿de qué exactamente? ¿De algo que somos o hacemos ahora? ¿De algo firme que practicamos de forma global? ¿Celebramos tal vez la pérdida de la inocencia? ¿Celebramos el sustrato identitario al que quiere remitirse la teoría (norteamericana)? Metahistory no ha cambiado el curso de la evolución de la disciplina histórica, ni en España ni fuera de España. La inestabilidad creada en la propia identidad de la disciplina no ha generado que se escriba ni que se imparta una historia nueva en las facultades de historia. Donde sí que parece que se ha operado un cambio (a peor) -como ya se ha señalado en esta reseña- es en el propio mundo de la teoría de la historia.

Desde mi punto de vista, la celebración de White es paradójicamente hoy la celebración de una de las piedras de toque de la academización de algo que nació para no ser academia. White parece uno de los lugares seguros en los que puede encastillarse la teoría convertida en saber académico.

¿Qué hay en Metahistory que lo hace tan proclive a ser utilizado como elemento esclerotizador de la teoría?

Por un lado, en el artículo de hercúleo título de Verónica Tozzi y Nicolás Lavagnino "Contingencias narrativas: re-escritura, responsabilidad cognoscitiva y el horizonte abierto de una interpretación pragmatista de la Nueva Filosofía de la Historia" (pp. 195-212) podemos percibir de qué modo los chispeantes planteamientos de White pasan a transformarse en una rígida carcasa de conocimiento escolástico. En él se plantea el (y no un) programa de investigación al que dio lugar la obra de Hayden White y se "sugiere una específica línea de diálogo con la filosofía pragmatista del conocimiento y de las ciencias" (p. 196; todas las cursivas son mías). Al lado de tales "programas" únicos y "líneas específicas" casi siempre asoma la cabeza la idea de una "lectura correcta" sea de este autor o de otros...y personalmente no creo en las "lecturas correctas".

Por otro lado, no cabe duda de que la aportación de Hayden White fue original y atrevida en su momento... pero en el fondo de ella hay un juego algo engañoso que ha favorecido la esclerosis académica. Aplicar la maquinaria de la crítica literaria al texto histórico no deja de ejercer un efecto de Ersatz de "análisis científico", de "prueba científica" que avala su tesis de que la historia no supera el marco de lo narrativo. El juego es aún mayor porque estoy convencido de que la gran mayoría de los admiradores de Hayden White no leyeron jamás ni a Michelet ni a Ranke, ni a Tocqueville ni a Burckhardt, y quizá tampoco (o tampoco lo suficiente) a Hegel, Marx, Nietzsche o Croce... Es decir, en buena parte de la recepción de White hay un cierto acto de fe intelectual en que todo lo que dice es plausible... es cierto. Lo imponente de su obra ha cerrado la puerta a la propuesta de que tal vez algunas de sus consideraciones sobre los autores concretos no sean asumibles o, al menos, no al 100\%. En libros como el de Bolaños no aparecen análisis exhaustivos del modo en el que el autor despliega la aplicación de los tropos en los diferentes autores. De White, se toma la conclusión global de que la aplicación a la historia de la teoría de los tropos ofrece una prueba infalible de las teorías de Metahistory y un camino metodológico franco.

Situar un antiguo libro partisano en el centro del debate actual generará siempre la sensación de que ese libro se encuentra de veras justamente en ese centro. Y ello no es 
así. El debate de la narratividad ha ido mucho más allá de White y ha adquirido formas diversas, a menudo extraacadémicas; la propia literatura (vamos a aceptar esta denominación para entendernos) plantea encrucijadas considerablemente abiertas y complejas, no solo ya con el -seguramente, a ojos de muchos-paleolítico Tolstoi (en el cual se encierran ya -y enunciados de un modo netamente teórico- elementos decisivos sobre la narratividad de la historia), sino sobre todo con García Márquez, Vonnegut, Rushdie o Eco. Y que no estamos hablando aquí del pasado, lo demuestran trabajos como los de Winfried Sebald o Emmanuel Carrère. El debate de la narratividad de perfil whiteano sigue extrañamente activo porque a la fábrica de History and Theory no se le ocurren más cosas; porque los Munslows, Runias, etc., no salen de una rueda en la que están muy cómodos y porque lo que en los 70 se anunciaba como incipiente revolución teórica se encuentra ahora durmiendo el sueño académico de los justos.

Por el contrario, tal vez el camino mejor para ser fieles hoy a la "revolución de White" - si alguna vez hubo tal cosa- sea atacar no tanto al viejo discurso de la historia sino a la estructura esclerotizada y muerta de las facultades de historia (y de la universidad en general) donde los saberes se agostan cada vez con más rapidez y donde la historia clásica, la revolucionaria, las teorías y las filosofías se desintegran de forma irremisible, víctimas de un adocenamiento y de una complacencia absolutamente vacíos, amparados por la estupidización global, en el caso de España, derivada de la catástrofe boloñesa y del imperio obsesivo e intelectualmente degradante de los evaluadores de la ANECA.

La forma de ser fiel a la posición del teórico y, por lo tanto, a la de aquel White de los años 70 es seguir indagando en cuáles son los obstáculos a la reflexión en libertad y seguir entendiendo la labor de la teorización como un proyecto intelectual arriesgado y palpitante.

Pedro Piedras Monroy

Universidad de Santiago de Compostela

pedropiedras@hotmail.com

Fecha de recepción: 21 de octubre de 2015.

Fecha de aceptación: 2 de noviembre de 2015.

Publicación: 31 de diciembre de 2015.

Para citar este artículo: Pedro Piedras Monroy, "Aitor Bolaños de Miguel (ed.), Metahistoria: 40 años después. Ensayos en homenaje a Hayden White. Logroño: Siníndice, 2014, 260 págs.”, Historiografías, 10 (julio-diciembre, 2015): pp.133-139. http://www.unizar.es/historiografias/historiografias/numeros/10/piedras.pdf 